\title{
Correction to: Street-scale storm surge load impact assessment using fine-resolution numerical modelling: a case study from Nemuro, Japan
}

\section{Ryota Nakamura ${ }^{1} \cdot$ Martin Mäll $^{2} \cdot$ Tomoya Shibayama $^{3}$}

Published online: 26 September 2019

(c) Springer Nature B.V. 2019

\section{Correction to: Nat Hazards https://doi.org/10.1007/s11069-019-03746-6}

This correction stands to correct two discrepancies reported to the publisher soon after publication. The authors and publisher regret the errors as they were caused by a proofing oversight and stress the following to be noted:

First, under the Methods and Material section (3.4), where the erroneous equation is:

$$
\begin{array}{ll}
C_{\mathrm{d}}=(1.0-0.01890 U) 10^{-3} & U<8 \mathrm{~m} / \mathrm{s} \\
C_{\mathrm{d}}=(1.0+0.1078 U) 10^{-3} & 8 \mathrm{~m} / \mathrm{s} \leq U, U \leq 30 \mathrm{~m} / \mathrm{s} \\
C_{\mathrm{d}}=0.00246 & U \leq 30 \mathrm{~m} / \mathrm{s}
\end{array}
$$

The correct equation should be:

$$
\begin{aligned}
& C_{\mathrm{d}}=(1.0-0.01890 U) \times 1.28 \times 10^{-3} U<8 \mathrm{~m} / \mathrm{s} \\
& C_{\mathrm{d}}=(1.0+0.1078 U) \times 0.581 \times 10^{-3} 8 \mathrm{~m} / \mathrm{s} \leq U, U \leq 30 \mathrm{~m} / \mathrm{s} \\
& C_{\mathrm{d}}=0.00246 \quad U>30 \mathrm{~m} / \mathrm{s}
\end{aligned}
$$

Second, for Figure 16 under the Results and Discussion section (4.2.4), a velocity scale bar in the original article ranges from $0.0 \sim 10.0 \mathrm{~m} / \mathrm{s}$. However, it should be $0.0 \sim 1.0 \mathrm{~m} / \mathrm{s}$. Provided in this correction is the correct rendering of the figure:

The original article can be found online at https://doi.org/10.1007/s11069-019-03746-6.

Ryota Nakamura

r-nakamura@eng.niigata-u.ac.jp

Martin Mäll

martin.maell@fuji.waseda.jp

Tomoya Shibayama

shibayama@waseda.jp

1 Civil Engineering Program, Faculty of Engineering, Niigata University, 8050 Ninocho, Ikarashi, Nishi-ku, Niigata-shi, Niigata 950-2181, Japan

2 Department of Civil and Environmental Engineering, Graduate School of Creative Science and Engineering, Waseda University, 3-4-1, Okubo, Shinjuku-ku, Tokyo 169-8555, Japan

3 Faculty of Science and Engineering, Waseda University, 3-4-1, Okubo, Shinjuku-ku, Tokyo 169-8555, Japan 


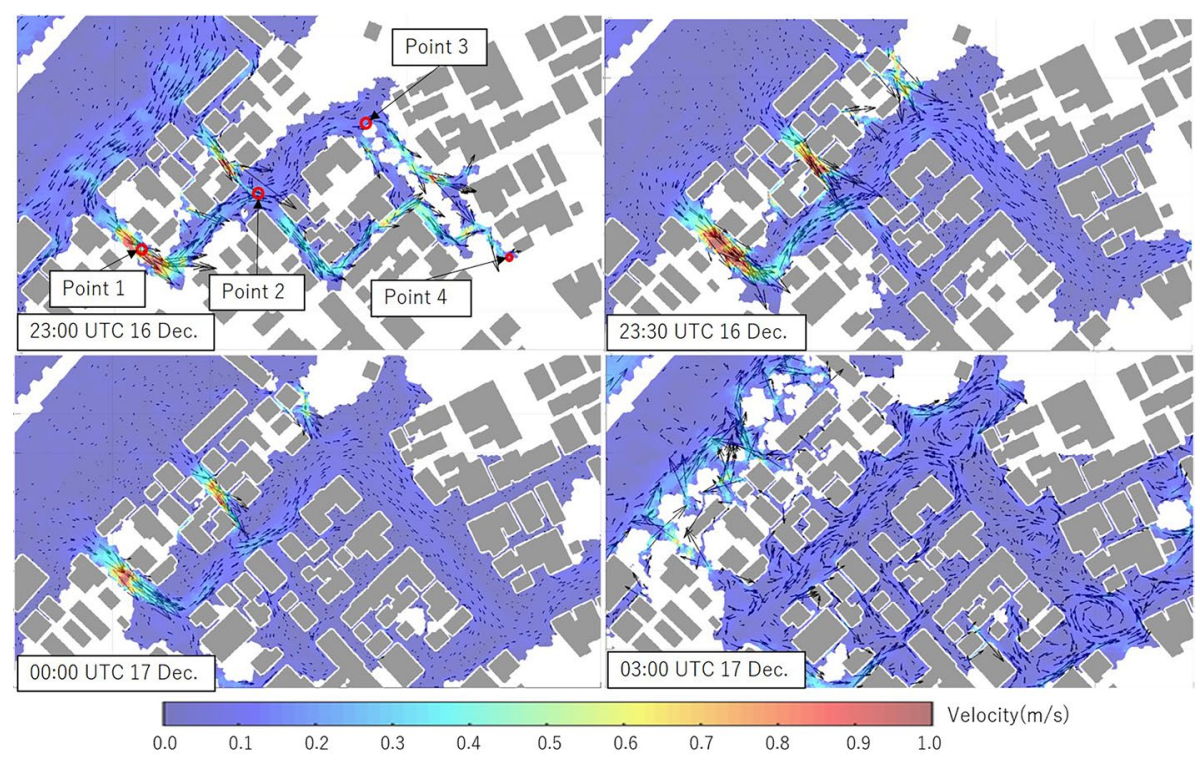

With attention to these corrections, the original article has been corrected.

Publisher's Note Springer Nature remains neutral with regard to jurisdictional claims in published maps and institutional affiliations. 